\title{
Disturbed gastric emptying in the short bowel syndrome. Evidence for a 'colonic brake'
}

\author{
J M D Nightingale, M A Kamm, J R M van der Sijp, G P Morris, E R Walker, S J Mather, \\ K E Britton, J E Lennard-Jones
}

\begin{abstract}
Gastric emptying of liquid (orange juice containing technetium-99m ( ${ }^{99 m} \mathrm{Tc}$ ) labelled antimony sulphide colloid) and solid $(570 \mathrm{kcal}$ pancake containing $0.5 \mathrm{~mm}$ resin microspheres labelled with Indiun-111 ("111-In)) was measured in seven patients with jejunum and no colon (jejunal lengths $30-160 \mathrm{~cm}$ ), six patients with jejunum in continuity with the colon (jejunal length $25-75 \mathrm{~cm}$ ), and in 12 normal subjects. In patients with no colon early emptying of liquid was rapid (median 25\% emptying: $7 v 25$ min, no colon $v$ normal, $p<0.05$ ); early gastric emptying of solid was rapid in two (each with less than $100 \mathrm{~cm}$ jejunum) and normal in the other five. Gastric emptying of liquid and solid for patients with jejunum in continuity with the colon was normal for the first three hours. There was increased liquid and solid retained in the stomach at six hours in both groups of patients $(p<0.01)$. Small bowel transit time was faster than in normal subjects for liquid in both groups of patients $(p<0.05)$ and for solid in those with no colon $(p<0.05)$. Rapid gastric emptying of liquid may contribute to the large stomal output in patients with a high jejunostomy. Preservation of the colon after a major small intestinal resection exerts a braking effect on the rate of early gastric emptying of liquid. (Gut 1993; 34: 1171-1176)
\end{abstract}

The number of patients surviving with a short length of residual small intestine is increasing.' This is as a result of, in part, the large number of patients who have had multiple bowel resections for Crohn's disease. ${ }^{2}$ Patients with a short remaining length of jejunum may be divided into two clinical groups: those with an end jejunostomy and those with jejunum in continuity with

TABLE I Patients details

\begin{tabular}{|c|c|c|c|c|c|}
\hline & Age/Sex & $\begin{array}{l}\text { Fejunal length } \\
(\mathrm{cm})\end{array}$ & $\begin{array}{l}\text { Original cause of } \\
\text { short bowel }\end{array}$ & $\begin{array}{l}\text { Time since last } \\
\text { small bowel resection } \\
\text { (months) }\end{array}$ & $\begin{array}{l}\text { Nutritional or } \\
\text { fluid supplements }\end{array}$ \\
\hline \multicolumn{6}{|c|}{ Short bowel with no colon } \\
\hline A & $32 \mathrm{~F}$ & 30 & Crohn's disease & 40 & HPN \\
\hline $\mathbf{B}^{\star}$ & $32 \mathrm{M}$ & 508 & Ulcerative colitis & 68 & HPN \\
\hline $\mathrm{C}$ & $36 \mathrm{~F}$ & 60 & Desmoid disease & 48 & HPN \\
\hline D & $62 \mathrm{~F}$ & 90 & Irradiation & 3 & Oral \\
\hline $\mathbf{E}$ & $61 M$ & 120 & Crohn's disease & 181 & Oral \\
\hline $\mathbf{F}$ & $70 \mathrm{M}$ & $130 \$$ & Crohn's disease & 127 & Oral \\
\hline & $55 \mathrm{M}$ & 160 & Crohn's disease & 146 & Oral \\
\hline \multicolumn{6}{|c|}{ Short bowel with a colon } \\
\hline $\mathrm{H}$ & $19 \mathrm{M}$ & 25 & Volvulus & 28 & HPN \\
\hline I† & $25 M$ & 25 & Volvulus & 36 & HPN \\
\hline J & $41 \mathrm{~F}$ & $70 \$$ & Adhesions & 72 & Oral \\
\hline $\mathrm{K} \dagger$ & $60 M$ & $75 \S$ & Ischaemia & 147 & None \\
\hline $\mathrm{L} \neq$ & $58 \mathrm{~F}$ & $75^{\circ}$ & Volvulus & 32 & Oral \\
\hline$M \ddagger$ & $51 M$ & 75 & Volvulus & 23 & None \\
\hline
\end{tabular}

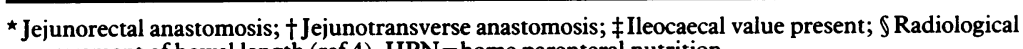
measurement of bowel length (ref 4). HPN=home parenteral nutrition a retained functioning colon. While both groups of patients with similar jejunal lengths have problems with nutrient absorption, jejunostomy patients also have high stomal losses of water and electrolyte ${ }^{23}$ causing serious problems in maintaining fluid balance. It was our hypothesis that these fluid losses may result not only from a reduction of absorptive capacity but also a disturbance of the regulation of gastric emptying.

In this paper we have studied the rate of gastric emptying for liquid and solid in patients with a short length of residual jejunum and no colon, a short jejunal length and a retained colon, and normal healthy volunteers. We have attempted to find out if the rate of emptying is different from normal in either group and whether preservation of the colon affects gastric emptying. The rate of solid and liquid transit through the small bowel has also been assessed.

\section{Subjects}

NORMAL SUBJECTS

Twelve healthy volunteers (eight women and four men) with a mean age of 32 years (range 19-53) and not receiving any treatment were studied. None had gastrointestinal symptoms or previous abdominal surgery.

PATIENTS (Table I)

All patients had had a previous resection of their ileum and part of their jejunum. The patients were clinically stable and well when studied at a median time of 48 months (range 3-181 months) after their last intestinal resection. All were maintaining a stable nutritional, fluid, and electrolyte state and all were taking an unrestricted oral diet. All the patients, except patient $J$, were well nourished and had a body mass index within the normal range. All the patients with previous inflammatory bowel disease had no evidence of current active disease as assessed clinically, radiologically, and biochemically. No patient had had gastric surgery.

Bowel length was measured at operation in nine and radiologically in four patients. We have previously shown a good correlation between radiological and surgical measurement of small intestinal length in patients with less than $200 \mathrm{~cm}$ small intestine. ${ }^{4}$

Short bowel with no colon - Six patients with an end jejunostomy and one patient with a jejunorectal anastomosis were included in this group. Four of these had less than $100 \mathrm{~cm}$ of jejunum remaining, of whom three required longterm home intravenous nutrition. The other four patients required oral nutritional or electrolyte 
supplements to maintain fluid balance and nutritional state.

Short bowel with a colon - Six patients with most of their colon in situ were studied. Two had their jejunum anastomosed to a short length of terminal ileum $(15 \mathrm{~cm}$ of ileum in patient $\mathrm{L}$, and $5 \mathrm{~cm}$ in patient $M$ ) and had a retained ileocaecal valve and whole colon, two had jejunum anastomosed to the caecum, and two jejunum anastomosed to the proximal transverse colon. Two patients, both with jejunal lengths of $25 \mathrm{~cm}$, were receiving longterm home intravenous nutrition. Two others took oral nutritional supplements and two others required no fluid or nutritional supplements.

\section{Method \\ All the patients stopped their anti-secretory drugs (octreotide, omeprazole, and ranitidine) at least one day before the start of the study. The anti-diarrhoeal drugs codeine and loperamide were stopped the evening before the start of the study; these drugs were not stopped earlier because of potential drug withdrawal symptoms. Women were studied during the first half of the menstrual cycle.}

A carefully devised meal was used to measure
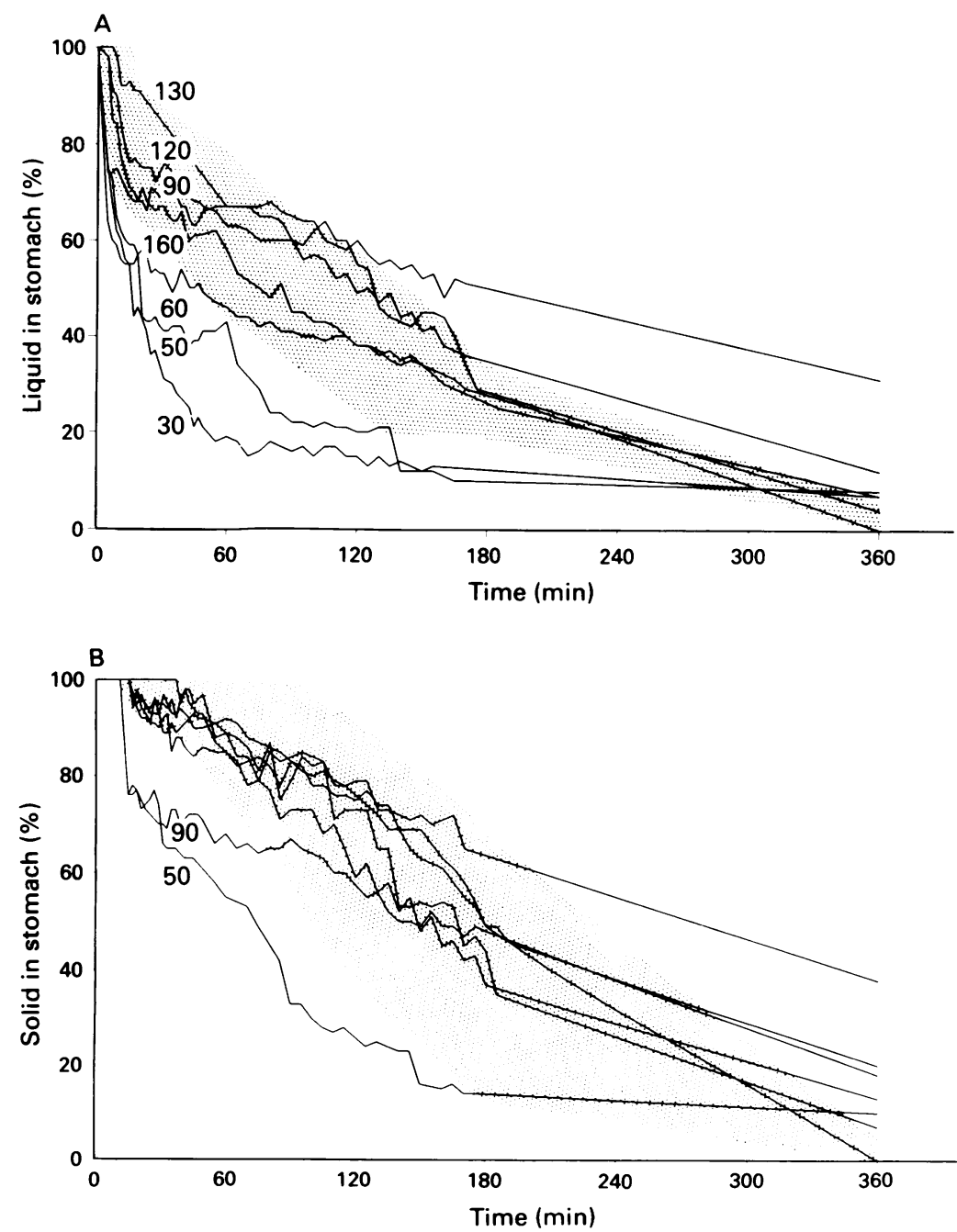

Figure 1: The percentage of the $(A)$ liquid and the $(B)$ solid phase of the meal remaining in the stomach after starting the orange juice or pancake for short bowel patients with no colon. The shaded area shows the normal range (2SDs) derived from the 12 normal subjects. The number on the graph show a patient's jejunal length. the gastric emptying of both liquid and solid phases. This technique has been previously evaluated, and shown to discriminate clearly between the two components of a meal in an acidic solution. ${ }^{+}$The solid phase consisted of a $570 \mathrm{kcal}$ pancake (cooked weight $220 \mathrm{~g}$ ) containing microspheres (mean diameter $0.5 \mathrm{~mm}$, range $0 \cdot 2-1.0 \mathrm{~mm}$ ) of an ion exchange resin (Amersham International, Buckinghamshire) labelled with $0.25 \mathrm{mCi}(10 \mathrm{MBq}$ ) indium-111 ('"In). The liquid phase consisted of $195 \mathrm{ml}$ orange juice (70 kcal) containing $1.0 \mathrm{mCi}(40 \mathrm{MBq})$ technetium-99m $\left({ }^{99 m} \mathrm{Tc}\right)$ bound to antimony sulphide colloid. The whole body dose of radiation was $0.06 \mathrm{rad}$ for ${ }^{11} \mathrm{In}$ (effective dose equivalent 3.0 $\mathrm{mSv}$ ) and $0.014 \mathrm{rad}$ (effective dose equivalent 0.5 $\mathrm{mSv}$ ) for ${ }^{99 \mathrm{~m}} \mathrm{Tc}$.

After fasting from midnight the pancake was eaten in the morning (about $10 \mathrm{am}$ ) over 10 minutes. The orange juice was then drunk after the pancake. Nothing else was eaten or drunk for the following six hours.

The gammacamera (Siemens model 7500, Germany) had a large field of view head and was fitted with a high resolution/medium energy parallel hole collimator. Dual isotope simultaneous scanning was carried out with the gammacamera peaked for $250 \mathrm{KeV}$ and $140 \mathrm{KeV}$ with $40 \%$ and $20 \%$ windows to detect the radiation from ${ }^{11}$ In and ${ }^{99 m} \mathrm{Tc}$ respectively. The combination of this pulse height analysis and the appropriate collumination reduced the effects of Compton scattering.

The pancake and orange juice were scanned before the meal was eaten so that a correction factor for the overlapping of the energy spectra of each isotope was derived. Scanning of the subject began within five minutes of completing the meal. Anterior and posterior static images of 30 seconds each were collected alternately every two minutes for $\mathbf{4 5}$ minutes; then every five minutes until three hours had passed, and then a final pair of scans at six hours. All images were taken with the subject standing in front of the camera.

This study was approved by the Ethical Committee of the City and Hackney District Health Authority in 1989 and all subjects gave informed consent. The radiation doses were at a level considered to be of negligible risk to members of the public by the International Committee on Radiation Protection.

\section{DATA ANALYSIS}

Gastric emptying - A 'region of interest' was drawn around the stomach and a count of the amount of radioactivity remaining in the stomach at each time was made. The counts derived were corrected for the overlapping of the energy spectra of each isotope, a geometric mean of anterior and posterior views were taken, and a correction made for decay of the radioisotopes. Time activity curves were created for the liquid and solid phases.

Lag time - The lag time was the difference in time from starting the meal till $10 \%$ of the solid had emptied from the stomach.

'Head of column' - small bowel transit - This was determined by visual inspection of the 


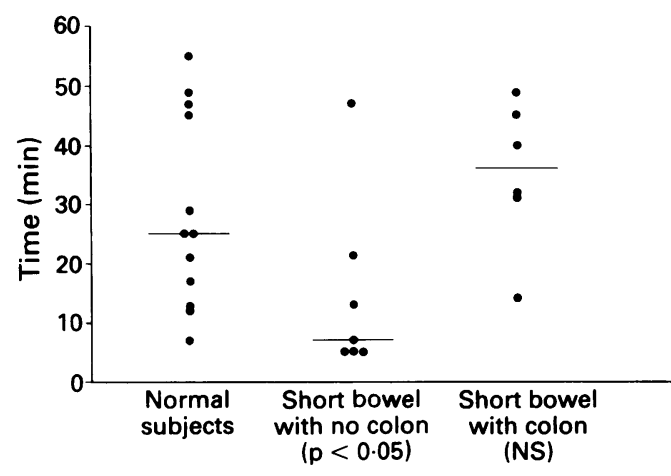

Figure 2: The time for $25 \%$ of the liquid to empty from the stomach in normal subjects, short bowel patients with and without a colon $(p<0 \cdot 05$, short bowel patients with no colon compared with normal subjects and compared with short bowe patients with a colon; NS=no significant difference between short bowel patients with a colon and normal subjects).

sequential scans in each subject and calculated as the difference in time between the start of the liquid and solid parts of the meal entering the duodenum and their arrival in the jejunostomy bag, colon, or rectum.

'Head of column' - mouth to stoma, colon, or rectum - The times taken from ingestion of liquid or solid till each of the isotopes entered the colon, rectum, or jejunostomy bag.

Statistical analysis - Comparisons between the amount of gastric emptying of normal subjects and each patient group were made using the Mann-Whitney U test.

\section{Results}

TOLERANCE OF PROCEDURE

All normal subjects ate the meal within 10 minutes. Patient A with no colon could not eat all of the pancake even after 20 minutes and left 80 g. Three patients with a colon found the meal difficult to finish: one (J) left $63 \mathrm{~g}$ after 25 minutes, two others ( $\mathrm{H}$ and $\mathrm{I})$ took 12 and 20 minutes to finish the meal. No subject had any problem drinking the orange juice.

PROBLEMS IN DETERMINING GASTRIC EMPTYING In one patient with no colon $(F)$ there was rapid gastric emptying and overlap of the proximal small bowel with the stomach, so that although early and late gastric emptying could be accurately assessed, the emptying from $21-60$ minutes had to be extrapolated. In four patients with a colon there was some overlap of the stomach by the transverse colon after an hour. In only one (H) did this contribute to more than $10 \%$ of the

TABLE II Lag time and time for 25 and $50 \%$ gastric emptying

\begin{tabular}{llllll}
\hline & & \multicolumn{2}{c}{$25 \%$} & \multicolumn{2}{c}{$50 \%$} \\
& Lag time & liquid & solid & liquid & solid \\
\hline Normal subjects & 65 & 25 & 108 & 98 & 150 \\
Patients & $(39-120)$ & $(7-55)$ & $(70-160)$ & $(29-120)$ & $(95-220)$ \\
Short bowel no colon & 53 & $7 \star$ & 110 & 90 & 170 \\
& $(15-70)$ & $(5-47)$ & $(21-130)$ & $(17-170)$ & $(75-320)$ \\
Short bowel with colon & 62 & 36 & 99 & 103 & 173 \\
& $(25-70)$ & $(14-49)$ & $(25-140)$ & $(74-139)$ & $(55-245)$ \\
\hline
\end{tabular}

Median results in minutes with range in brackets; ${ }^{\star}=\mathrm{p}<0.05$ compared with normal subjects. counts. In this patient $(\mathrm{H})$ the data between 120 and 180 minutes have been extrapolated, but the data at $\mathbf{3 6 0}$ minutes are a real measurement as there was no longer overlap of the stomach and colon.

DETERMINATION OF NORMAL RANGE

For both liquid and solid a normal range of gastric emptying was obtained by determining the mean ( $2 \mathrm{SDs}$ ) of the residual radioisotope count in the stomach at each time point for all the normal subjects.

\section{GASTRIC EMPTYING IN PATIENTS WITH NO COLON (Fig 1)}

\section{Liquid}

The time for $25 \%$ of the liquid to have emptied from the stomach (Table II, Figs 1 and 2) was significantly faster in patients with no colon compared with normal subjects $(\mathrm{p}<0.05)$ and with those with a colon $(p<0 \cdot 05)$. The four patients with no colon and with less than $100 \mathrm{~cm}$ jejunum had all emptied $25 \%$ of the liquid phase within seven minutes (Fig 2). The fastest rates of liquid emptying occurred in those with the shortest length of jejunum (for jejunal length against $25 \%$ emptying (Fig 3): $r=0.57, \mathrm{p}=0 \cdot 18$, $50 \%$ emptying: $r=0.66 \mathrm{p}=0 \cdot 11)$. Although the $50 \%$ emptying of liquid was not significantly different from normal for the patient group as a whole, it was faster than normal in three patients (Fig 1A).

The amount of liquid in the stomach at six hours was significantly increased compared with normal subjects $(p<0.01)$ and in five patients was more than the normal mean $(2 \mathrm{SDs})(7,7,8$, 12 , and $31 \%$ ).

\section{Solid}

Early gastric emptying of solid was normal in five patients and rapid in two, both of whom had less than $100 \mathrm{~cm}$ jejunum.

The amount of solid in the stomach at six hours was significantly increased compared with

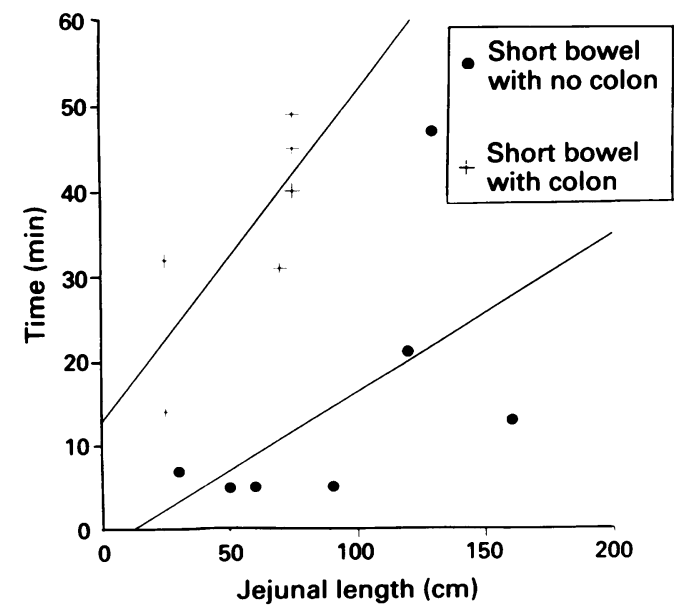

Figure 3: Graphs of time of 25\% gastric emptying of liquid against the residual jejunal length for short bowel patients with no colon $(r=0.57, p=0 \cdot 18)$ and short bowel patients with $a$ colon $(r=0.78, p=0.07)$. 
normal subjects $(\mathrm{p}<0.01)$ and in six patients was more than the normal mean $(2 \mathrm{SDs})(7,10,13$, 18,20 , and $38 \%$ ).

TABLE III 'Head of column' transit time

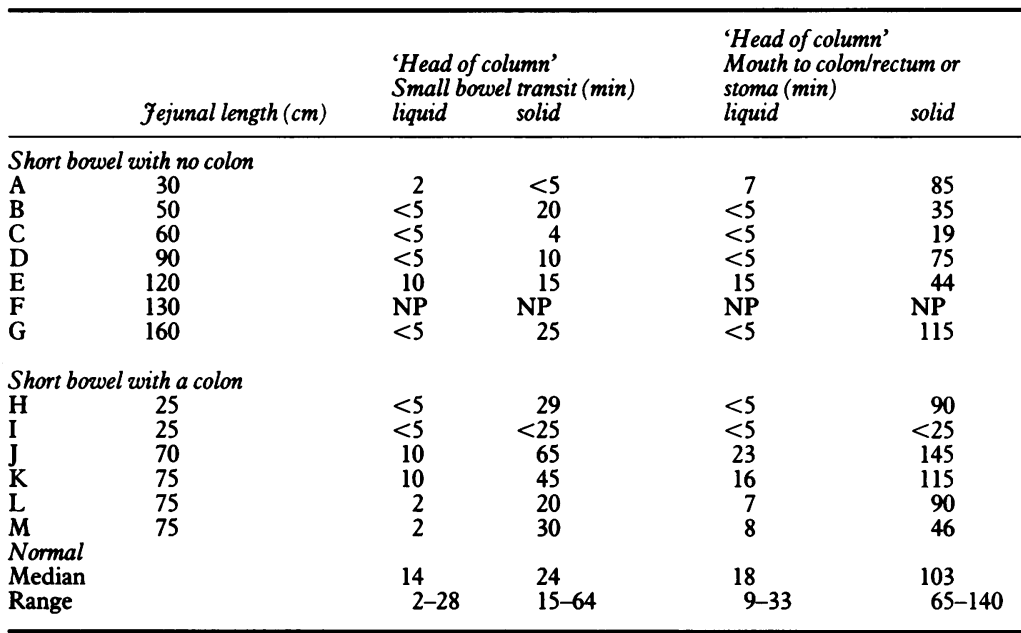

$\mathrm{NP}=$ In patient $\mathrm{F}$, it was not possible to tell when the solid entered the jejunostomy bag as the bag was not shown on the screen.
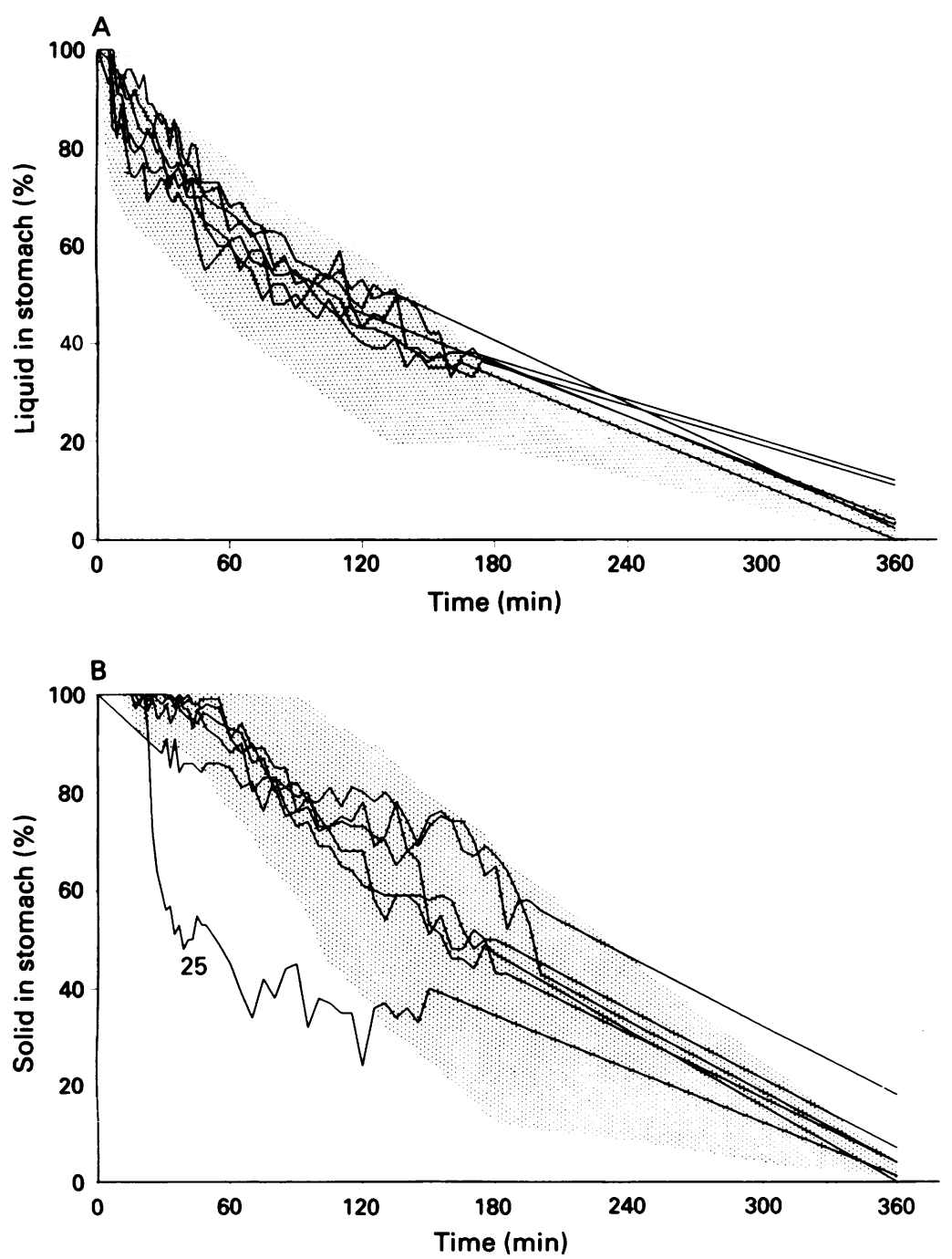

Figure 4: The percentage of the $(A)$ liquid and $(B)$ solid phase of the meal remaining in the stomach after starting the orange juice or pancake for short bowel patients with a colon. The shaded area shows the normal range (2SDs) derived from the 12 normal subjects. The numbers on the graph show a patient's jejunal length.

\section{GASTRIC EMPTYING IN PATIENTS WITH A COLON} (Fig 4)

\section{Liquid}

The gastric emptying of liquid in all patients with a colon was normal. There was a tendency for those with the shortest jejunal length to have the most rapid gastric emptying (for jejunal length against $25 \%$ emptying (Fig 3): $r=0.78$, $\mathrm{p}=0.07,50 \%$ gastric emptying $r=0.82$, $\mathrm{p}<0.05)$.

The amount of liquid in the stomach at six hours was significantly increased compared with normal subjects $(p<0.05)$, however in only two patients was it by more than the normal mean (2SDs) (11 and 12\%).

\section{Solid}

Only one patient (I) with $25 \mathrm{~cm}$ jejunum anastomosed to transverse colon had rapid emptying of the solid, the others had normal gastric emptying of solid.

The amount of solid in the stomach at six hours was not significantly different from normal subjects $(p=0.06)$, though in two patients was more than the normal mean (2 SDs) $(7$, and $18 \%)$.

\section{LAG TIME}

This was not significantly different between both groups and normal subjects (Table II).

'HEAD OF COLUMN' - SMALL BOWEL TRANSIT

Visual determination of the entry of radioisotope into the duodenum and then into the colon, rectum, or stoma bag was not usually difficult.

The small bowel transit time for liquid (Table III) was faster in both groups of patients compared with normal subjects (median $<5$ min no colon, $<5 \mathrm{~min}$ with a colon, $14 \mathrm{~min}$ normal subjects, $\mathrm{p}<0.05$ both groups of patient compared with normal subjects).

The small bowel transit time for solid was faster in those with no colon compared with normal subjects (median 13 min no colon, $24 \mathrm{~min}$ normal subjects, $\mathrm{p}<0.05$ ) but not in those with a colon (median $30 \mathrm{~min}, \mathrm{p}=0.09$ ).

'HEAD OF COLUMN' - MOUTH TO STOMA, COLON, OR RECTUM

The mouth to stoma, colon, or rectum transit time for liquid (Table III) was faster in both groups of patients compared with normal subjects (median $<5$ min no colon, 8 min with a colon, $18 \mathrm{~min}$ normal subjects, $\mathrm{p}<0.05$ both groups of patient compared with normal subjects).

The mouth to stoma, colon, or rectum transit time for solid was not significantly different from normal subjects in either group (median $60 \mathrm{~min}$ no colon, $90 \mathrm{~min}$ with a colon, $103 \mathrm{~min}$ normal subjects).

\section{Discussion}

This study shows that patients with a jejunostomy 
and less than $100 \mathrm{~cm}$ jejunum have rapid early gastric emptying of liquids, and in some also solids. The rate of early gastric emptying of liquid tended to correlate with jejunal length. This rapid rate of early gastric emptying probably contributes to the high intestinal output. Gastric emptying of solid was rapid in two of seven patients with no colon, both with less than $100 \mathrm{~cm}$ jejunum, and normal in the others. In addition to a disturbance of early gastric emptying they also have an abnormality of late gastric emptying with both liquid and solid being retained in the stomach at six hours. Patients with a similar jejunal length but in continuity with the colon, have normal gastric emptying of liquids and solids.

Patients with a short bowel often have difficulty consuming a large meal. Two patients were marginally slow to finish the meal and two others consumed most, but not all of the meal. The variations in meal consumption were small and unlikely to influence the final results.

Previous studies in animals have shown that after a jejunal resection gastric emptying of liquid is normal, ${ }^{67}$ but after an ileal resection it may be fast ${ }^{6}$ or slow. ${ }^{7}$ Previous studies in humans have shown that after a distal small intestinal resection but with retention of the colon, the gastric emptying of liquids is normal. ${ }^{8}$ If the colon is removed in addition to the terminal ileum the gastric emptying of solids is normal. These findings are in agreement with our findings.

The rate of gastric emptying is normally controlled by both neural and humoral mechanisms so that chyme is delivered into the intestine at a rate optimal for digestion and absorption. Several factors relating to the meal are known to slow gastric emptying such as a large volume, ${ }^{10}$ high nutrient density, ${ }^{11}$ a hyper or hypo-osmolar solution, ${ }^{12}$ or acid. ${ }^{13}$ External factors, for example a painful stimulus, will also delay gastric emptying. ${ }^{14}$

The upper small intestine normally plays an important part in regulating the rate of gastric emptying. Studies in dogs have shown that the longer the length of duodenum and jejunum exposed to glucose, ${ }^{15}$ acid, ${ }^{16}$ or sodium oleate ${ }^{17}$ the greater the delay in gastric emptying. This jejunal braking mechanism is probably reduced in most patients studied, as much of the jejunum had been resected. This braking mechanism may have been active in those patients with no colon and more than $90 \mathrm{~cm}$ residual jejunum as their rate of gastric emptying was within the normal range.

Different nutrients affect both gastric emptying and small intestinal transit by different mechanisms. An infusion of lipid ${ }^{18-20}$ protein hydrolysate $^{21}$ or carboydrate 2223 into the ileum delays proximal small bowel transit. Of these stimuli in the ileum lipid ${ }^{19225}$ and carbohydrate ${ }^{26}$ have also been shown to delay gastric emptying. Further evidence for two mechanisms, one which delays gastric emptying and the other which delays small bowel transit, comes from experiments that show that intravenous naloxone prevents intralipid infused into the ileum from slowing small bowel transit but does not prevent it from slowing gastric emptying. ${ }^{2728}$
There is also evidence that events within the colon affect the rate of gastric emptying. Balloon distension in the colon or rectum of animals causes a rapid inhibition of gastric and intestinal contractions and tone, ${ }^{29-32}$ probably as a result of a neural mechanism as the effect can be abolished by splanchnic nerve excision..$^{30}$ There is also, however, a humoral component as balloon inflation of the rectum causes delayed inhibition of motility in denervated jejunal loops. ${ }^{32}$ Youle and Read performed paired studies of gastric emptying in healthy human subjects with and without intermittent painless rectal distension, using a 150 or $200 \mathrm{ml}$ balloon. ${ }^{33}$ This delayed both gastric emptying and intestinal transit of a solid meal. There are thus at least four gastrointestinal sites which, depending on their lumenal contents, may effect gastric emptying: the stomach itself, the proximal small bowel, the distal small bowel, and the colon and rectum.

Both groups of patients studied had had a major jejunoileal resection so that much of the jejunal and most of the ileal braking system has been removed. With the loss of these mechanisms the rate of gastric emptying would be expected to be fast. We have shown this to be the case in patients with a high jejunostomy, especially for liquid, but if the colon is preserved gastric emptying remains normal pointing to the presence of a 'colonic brake'.

When just the 'head' of the liquid component of the meal is considered, both groups of patients with a short bowel showed rapid early transit from the mouth to the end of the small bowel (Table III). For the bulk of the meal (for example 25 or $50 \%$ gastric emptying) however, the gastric emptying rate for liquid is normal (Fig 2) in those with a colon. This suggests that a 'colonic brake' comes into play and is activated by the early arrival of liquid in the colon. This 'brake' allows gradual entry of nutrients into the small intestine so that the time for absorption is maximal.

The braking mechanism may be neural by colonic sensory receptors, or humoral because of a hormone produced by the colon. Enteroglucagon $^{33}$ and PYY $^{34}$ producing cells are abundant in the colon and these hormones may compensate for the loss of jejunal and ileal inhibitory factors.

The reason for a significantly increased gastric residue of both liquid and solid at six hours in both patient groups (but most pronounced in those with no colon) is not clear. After the bulk of a meal has been emptied from the stomach, 'fasting' activity resumes. Interdigestive migrating complexes are thought to be responsible for clearing the remainder of the meal from the stomach ${ }^{35}$ Remmington et al showed in patients with a short bowel, most of whom had a retained colon, that the interdigestive migrating complex occurred more frequently but for a shorter total duration than normal, and that phase 2 activity was also of a shorter duration. ${ }^{36}$ It may be that there is a disturbance of interdigestive migrating complexes, especially in patients without a colon. Parenteral nutrition can delay gastric emptying of solid, ${ }^{37}$ but the five of our patients normally receiving this treatment (two with a colon and three without) had stopped the infusion at least two and a half hours before the study. 
The clinical significance of a larger than normal gastric residue at six hours in both groups is unknown.

Intestinal transit for the 'head' of a liquid and solid meal was faster in both groups of patients than normal subjects. Small bowel transit has been shown in animals to be fast after a distal, and slow after a proximal, resection. ${ }^{6738}$ This may reflect the normal fast transit through the jejunum and slow transit through the ileum..$^{39} 40$ Our patient's transit times are likely to be rapid because of faster jejunal transit and a shorter distance to travel. The normal time for solid transit in those with a retained colon indicates very slow transit through a given length of jejunum.

These patients with a short bowel with and without a colon provide a unique physiological model from which to discover more about the factors that regulate gastric emptying and small bowel transit. We have shown that preservation of the colon in patients with a short bowel provides a braking mechanism to gastric emptying so transit time is normal, allowing adequate time for liquid absorption. This is lacking in those with a high jejunostomy so that rapid early gastric emptying occurs, particularly of liquid, which may contribute to high stomal losses.

We are grateful for the use of the facilities of the Imperial Cancer Research Fund. We thank David Ellison for his technical assistance in preparing the meal.

1 Stokes MA, Almond DJ, Pettit SH, Mughal MM, Turner M, Shaffer JL, et al. Home parenteral nutrition: a review of 100 patient years of treatment in 76 consecutive cases. Br 7 Surg patient years of treat
$1988 ; 75: 481-3$.

2 Nightingale JMD, Lennard-Jones JE, Gertner DJ, Wood SR, Bartram CI. Colonic preservation reduces the need for parentral therapy, increases the incidence of renal stones but does not change the high prevalence of gall stones in patients with a short bowel. Gut 1992; 33: 1493-7.

3 Nightingale JMD, Lennard-Jones JE, Walker ER, Farthing MJG. Jejunal efflux in short bowel syndrome. Lancet 1990; 336: $765-8$.

4 Nightingale JMD, Bartram CI, Lennard-Jones JE. Length of residual small bowel after partial resection: Correlation residual small bounic and surgical measurements. Gastrointest Radiol 1991; 16: 305-6.

5 Mather SJ, Ellison D, Nightingale JMD, Kamm MA, Britton KE. The design of a two-phase radio-labelled meal for KE. The design of a two-phase radio-labelled meal for gastric

6 Nylander G. Gastric evacuation and propulsive intestinal motility following resection of the small intestine in the rat. Acta Chir Scand 1967; 133: 131-8.

7 Reynell PC, Spray GH. Small intestinal function in the rat after massive resections. Gastroenterology 1956; 31: 361-8.

8 Dew MJ, Harries AD, Rhodes M, Rhodes J, Leach KG. Gastric emptying after intestinal resection in Crohn's disease. BrF Surg 1983; 70: 92-3.

9 Neal DE, Williams NS, Barker MJC, King RFGJ. The effect of resection of the distal ileum on gastric emptying, small bowel transit and absorption after proctocolectomy. $\mathrm{Br} \mathcal{F}$ Surg 1984; 71: 666-70.

10 Hunt JN, MacDonald I. The influence of volume on gastric emptying. F Physiol 1954; 126: 459-74.

11 Hunt JN, Stubbs DF. The volume and energy content of meals as determinants of gastric emptying. $\mathcal{F}$ Physiol 1975; 245: 209-25.

12 Hunt JN. Some properties of an alimentary osmoreceptor mechanism. F Physiol 1956; 132: 267-88.

13 Hunt JN, Pathak JD. The osmotic effects of some simple molecules and ions on gastric emptying. $\mathcal{F}$ Physiol $1960 ; 154$ $254-69$.
14 Thompson DG, Richelson E, Malagelada J-R. Perturbation of upper gast

15 Lin HC, Doty JE, Reedy TJ, Meyer JH. Inhibition of gastric emptying by glucose depends on length of intestine exposed emptying by glucose depends on length of intest

16 Lin HC, Doty JE, Reedy TJ, Meyer JH. Inhibition of gastric emptying by acids depends on $\mathrm{pH}$, titratable acidity, and length of intestine exposed to acid. Am F Physiol 1990; 259: G1025-30.

17 Lin HC, Doty JE, Reedy TJ, Meyer JH. Inhibition of gastric emptying by sodium oleate depends on length of intestine exposed to nutrient. Am F Physiol 1990; 259: G1031-6.

18 Spiller RC, Trotman IF, Higgins BE, Ghatei MA, Grimble GK, Lee YC, et al. The ileal brake-inhibition of jejunal motility after ileal fat perfusion in man. Gut 1984; 25 365-74.

19 Holgate AM, Read NW. Effect of ileal infusion of intralipid on gastrointestinal transit, ileal flow rate, and carbohydrate absorption in humans after ingestion of a liquid meal. Gastroenterology 1985; 88: 1005-11.

20 Spiller RC, Trotman IF, Adrian TE, Bloom SR, Misiewicz JJ, Silk DBA. Further characterisation of the 'ileal brake' reflex in man - effect of ileal infusion of partial digests of fat, protein, and starch on jejunal motility and release of neurotensin, enteroglucagon, and peptide YY. Gut 1988; 29 : 1042-51.

21 Read NW, McFarlane A, Kinsman RI, Bates TE, Blackhall NW, Farrar GB, et al. Effect of infusion of nutrient solution into the ileum on gastrointestinal transit and plasma levels of neurotensin and enteroglucagon. Gastroenterology 1984; 86: 274-80.

22 Spiller RC, Trotman IF, Silk DBA, Lee YC, Ghatei MA Bloom SR, et al. Control of jejunal motility by ileal contents and hormones in man. Gastroenterology 1983; 84: 1319.

23 Jain NK, Boivin M, Zinsmeister A, Brown ML, Malagelada J-R DiMagno EP. Effect of ileal perfusion of carbohydrates and amylase inhibitor on gastrointestinal hormones and emptying. Gastroenterology 1989; $96: 3$

24 Fone DR, Horowitz M, Read NW, Dent J, Maddox A. The effect of terminal ileal triglyceride infusion on gastroduodenal motility and the intragastric distribution of a solid meal. Gastroenterology 1990; 98: 568-75.

25 Welch I McL, Cunningham KM, Read NW. Regulation of gastric emptying by ileal nutrients in humans. Gastroenterology 1988; 94: 401-4.

26 Layer P, Zinsmeister AR, DiMagno EP. Effects of decreasing intraluminal amylase activity on starch digestion and postprandial gastrointestinal function in humans. Gastroenterology 1986; 91: 41-8.

27 Read NW, Welch I McL. Naloxone prevents the effect of ilea lipid on small bowel transit but not on gastric emptying. Gut 1984; 25: A1326.

28 Kinsman RI, Read NW. Effect of naloxone on feedback regulation of small bowel transit by fat. Gastroenterology 1984; 87: 335-7.

29 Pearcy JF, Van Liere EJ. Studies on the visceral nervou system. Am F Physiol 1926; 78: 64-73.

30 Youmans WB, Meek WJ. Reflex and humeral inhibition in unanaesthetised dogs during rectal stimulation. $A m$ Physiol 1937; 120: 750-7.

31 Morin G, Vial J. Champ de l'inhibition reflexe provoque de par la distension de l'intestin. Compt rend Soc de Biol 1934; 113: $1540-1$

32 Lalich J, Meek WJ, Herrin RC. Reflex pathways concerned in inhibition of hunger contractions by intestinal distenstion. Am 7 P hysiol 1936; 115:410-4.

33 Youle MS, Read NW. Effect of painless rectal distention on gastrointestinal transit of solid meal. Dig Dis Sci 1984; 29 . gastroin

34 Adrian TE, Savage AP, Fuessl HS, Wolfe K, Besterman HS Bloom SR. Release of peptide YY (PYY) after resection of small bowel, colon or pancreas in man. Surgery 1987; 101 $715-9$.

35 Itoh Z, Aizawa I, Sekiguchi T. The interdigestive migrating complex and its significance in man. Clin Gastroenterol 1982; 11: 497-521.

36 Remington M, Malagelada J-R, Zinsmeister A, Fleming CR. Abnormalities in gastrointestinal motor activity in patients with short bowels: Effect of a synthetic opiate. Gastroenterology 1983; 85: 629-36.

37 MacGregor IL, Wiley ZD, Lavigne ME, Way LW. Tota parental nutrition slows gastric emptying of solid food. Gastroenterology 1978; 74: 1059.

38 Booth CC. The metabolic effects of intestinal resection in man. Postgrad Med F 1961; 37: 725-39.

39 Singleton AO, Redmond DC, McMurray JE. Ileocecal resection and small bowel transit and absorption. Ann Sur 1964; 159: 690-4.

40 Summers RW, Kent TH, Osbourne JW. Effects of drugs, ilea obstruction and irradiation on rat gastrointestina propulsion. Gastroenterology 1970; 59: 731-9. 